Editorial

\title{
Knowledge Flow and Capacity Development: An Introduction to the Special Issue
}

Higher Education Policy (2005) 18, 199-205. doi:10.1057/palgrave.hep.8300083

This Special Issue of Higher Education Policy is concerned with how knowledge flows affect educational capacity, particularly in countries of the 'South'. The advent of the knowledge economy, or knowledge society, has placed a new value on the creation and distribution of ideas, and the provision of information. Knowledge is power, and increasingly so. This ethos is, for instance, key to the European Union's (EU) Lisbon Agenda, which aims to make Europe the most competitive and dynamic knowledge-based economy in the world. Importantly, the EU sees this drive as conferring advantages not only just in terms of economic growth but also through creating 'better' jobs and greater social cohesion. The EU has therefore developed a number of important 'instruments' to facilitate it to act strategically. That is, to link actions to goals and funding to policy. This Special Issue aims to highlight some issues that are important in the strategic response to knowledge flow and capacity development, particularly among some countries in Africa and Asia-Pacific.

There has perhaps never been a more exciting time for those who produce and present 'knowledge' - and this activity reaches far beyond the confines of academia. Indeed, the discipline-orientated approach of much academic teaching and research can seem somewhat naïve in the context of real-world social and policy issues. However, the utilitarian emphasis on the 'users' of knowledge, while not necessarily problematic in itself, if over-interpreted can dampen down interest and investment in the more 'esoteric', or more 'pure' types of knowledge reification. As the former Director General of UNESCO Frederico Major has stated, 'There is no applied science, if there is no science to apply'.

In many low-income countries in the South, the idea of a 'knowledge society' could become a means of proselytizing the minds of their inhabitants literally getting them to think like those from, by and large, economically stronger Northern countries. The South becomes a market for the exportation of perhaps Euro-centric or North American or corporate knowledge. The South may also become a source of 'knowledge workers' for the North. In this volume, we are therefore particularly interested in the dynamic between 
knowledge from elsewhere and more local knowledge, and to what extent the balance of these constitute capacity building or capacity stripping. In focusing on the 'South', we are acutely aware of the range of economic and social strengths to be found there, and also that the contributions to this volume are in no way representative of the diverse array of Southern Hemisphere countries. One value of focusing on the context of some southern countries is to recognize that knowledge is not neutral, it comes from somewhere, and it often points towards certain ways of understanding the world. All countries, North and South, are undergoing a process of socio-economic change, some faster than others, but each is affected by the global pulse of change, either willingly or unwillingly, and usually both. Such is the complexity of socioeconomic change consequent from globalization that it is clear no single corpus or source of knowledge determined by national imperatives alone can adequately address the many cross-national challenges that we now face (MacLachlan and Caball, 2004).

For the sake of clarity, we define knowledge flows as the movement and availability of information. We also acknowledge that the very term 'knowledge' is somewhat loaded in that it is often taken to infer the 'correctness' of information. We recognize that the propriety of knowledge not only depends on its context of application but also that a degree of relativity is necessary in order to respect and facilitate the interplay between different sources of knowledge. We define capacity building as enhancing the ability to make optimal use of resources. In this Special Issue, we are therefore particularly concerned with how the movement and availability of information can enhance the ability to make optimal use of resources. The articles in this volume demonstrate the exciting and sometimes difficult dynamic at play between local and global interpretations of this process. For instance, Neave (2002) outlines how capacity development is impacted by knowledge flows fuelled by global mobility. 'Brain drain' favors the materially wealthier nations, although there remain opportunities for knowledge gain by less wealthy counterparts (Marsella, 1998).

Many of the contributors to this volume are psychologists whose greatest emphasis is on people: the human conduits of knowledge flows. Understanding 'people' in knowledge flow and capacity development is another distinguishing feature of this Special Issue. Complementing perspectives from politics (Olsen et al., 2004), economics (Potter, 2004), development studies (Tilak, 2002), and higher education (HE) (Varis et al., 2003; Enders and Fulton, 2004), we present a psychological analysis of the human resource (HR) implications of knowledge flows and capacity building. As such, needs identified by the International Association of Universities - from 'development cooperation' to 'linkages' and 'academic mobility' (Knight, 2003) — are viewed through the lens of human factors. 


\section{The Contributions in Brief}

Hugo's paper considers aspects of HR flows in Australian HE. The reasons for global mobility, he argues, are multi-factorial. Knowledge flow and capacity development are as much about the pushes and pulls of lifestyle, identification, and family incentives, as they are about opportunities for career advancement. Nor is creating sustainable development in HE simply about hiring 'new' academics to replace the talent that is about to retire. Inexperienced academics require mentors to help them learn how to carry the kinds of administrative and teaching loads that managerial pressures have imposed (below, Meyer and Evans). Hugo concludes with a range of practical recommendations for enhancing capacity and knowledge flow. These center on promoting diversity, for example, in age and gender, across the national system.

Although net knowledge flows may be reducing capacity in the Australian setting, in Africa they are literally life threatening. McAuliffe and MacLachlan focus on capacity development among health professionals and in particular how the mobility of health professionals and international agreements on intellectual property rights have created a capacity-stripping environment, in the very places where capacity building is perhaps most needed. They highlight motivational HR issues and the development of local alternatives to highly paid and highly mobile health professions, as two possible factors in strengthening health delivery systems in low-income countries. They also argue for the moral necessity of more globally equitable knowledge flows.

Building capacity locally rather than globally is an issue probed by Meyer and Evans. They consider how capacity depends on knowledge flowing between academics themselves. The psychology of academic interaction has, they argue, been overlooked in research, despite the fact that it is the faculty who are at the heart of organizational change. Motivation theory needs to be applied to enhance, and help develop, human capacity. A critical vehicle for that application is the transmission of experience through academic mentoring and leadership. Traversing such straits requires an appreciation that one size does not fit all, and that there are recognizable individual and group differences in how different faculty will respond to a diverse range of possible incentives. Salient splitting factors include career stage, family circumstances, cultural values, control beliefs, performance expectations, and cognitive ability. Meyer and Evans conclude with a range of HR policy initiatives, for improving knowledge flow and capacity development among the Professoriate.

Maluwa-Banda and MacJessie-Mbewe describe how constraints, on students and staff alike, affect motivation for both groups in Malawi. For instance, there are often no texts, even foreign ones, overly onerous teaching loads, and materially poor conditions of service, despite the high social value placed on 
education as civil service. These shortages conspire to demean the culture of teaching, learning, and research — deflecting it from a critical 'problem posing' to a 'knowledge banking' metaphor. Rote learning and storage necessarily become important. Thus, learning styles are perhaps as much shaped by an impoverished socio-economic context as they are by culture or other socio-dynamic processes. Ripple effects from such deflections are especially wide when the domain is education (Schwartz, 1997). Solutions require networking through digital technology, regional cooperation, and resonating directly with the previous paper - career planning.

Changing the culture of education is a theme reprised in Sinlarat's contribution. Despite best intentions, development initiatives such as technical assistance (expatriate aid) and 'user collect' knowledge flow systems (such as the Columbo Plan) have fostered cultures of knowledge reception rather than knowledge production in Thailand. Universities have, in fact, stripped capacity: indigenous knowledge has been progressively devalued and discarded, with opportunities for synergy with more Western-orientated education overlooked. Sinlarat argues that globalization has assisted by encouraging the universities (that are primarily orientated towards Western values and interests) to produce a workforce to serve the governmental and business sector interests. Re-rendering Thai HE relevant, and genuinely enhancing capacity, requires a change in the culture of education itself, towards greater integration of global and local (traditional) knowledge systems.

A similar line of argument is given from Papua New Guinea by Marai, Haihuie, and Kavanamur. They too suggest that Western-style HE has in the long run been counterproductive, both for Papua New Guinea's graduates and the country's national development. Like the previous paper, these writers argue that a combination of both indigenous and relatively globalized knowledge systems, and knowledge flow between the two in the local context, is the best way forward for developing capacity. Again therefore, the way forward is seen to consist of fuelling integration between global and local systems of knowing.

Addressing that possibility in Cameroon, Nsamenang delineates provides a historical analysis of the differing strands of cultural influence that have acted over centuries of migratory perturbations to disorganize indigenous development. Instead of appreciating this psycho-historical process, however, contemporary discourse continues to implicitly devalue indigenous knowledge systems, thereby perpetuating the cycle itself. As a result, knowledge flows remain minimal, capacity is undermined, and dependence on foreign assistance continues - even among the countries' educated elites. Solutions involve recultivating traditional metaphors for human development, including traditional 'learning postures' and renewed appreciation of diversities of knowledge within the HE system. 
Focusing on this theme while training health professionals in Malawi, Bandawe notes how traditional metaphors may be applied to enrich the flow, between global and local systems of knowing, in HE in Malawi. Bandawe reveals how the concept of $u$ Munthu adds an ethical motivation to HE and training, in the health sciences. The concept of $u$ Munthu directly challenges the relativity of Western-based understandings of the self as an individualized and self-motivating entity, by presenting the notion that 'a person is a person, through other persons'. The challenge of course is to present these alternatives in ways that allow both global and local knowledge to be considered in ways that are essentially productive and creative (Neave, 2002).

The 'interface' between traditional and relatively localized, plus contemporary and often relatively globalized knowledge systems, is explored by Durie. Anchored, but not bounded, in HE within bicultural Aotearoa/New Zealand, Durie traces the historical interactions of colonialism with indigenous peoples. Distilling a range of commonalities in their experiences, and complementing Sinlarat, Durie notes that the point of contact between these systems has been shifting from 'lands, waterways, and oceans' to 'intellectual and cultural sites,' including the universities. Those interactions are not seen as zero-sum games however. Both teaching and research can and do appreciate each perspective. Interfaces like this produce synergies in both teaching and research, for example, in health. The interface can be a space where knowledge genuinely flows. Capacity is therein enhanced and universities - through the establishment of localized centers of excellence - regain responsiveness to (bicultural) society.

Creating spaces for global and local knowledge systems to interact is the topic explored by Inkson and Parker. Stepping outside the borders of HE itself, knowledge flow and capacity development are not the sole preserve of the academe. With career theory as a foundation and the film industry in New Zealand as an example, Inkson and Parker describe the formation, outside the university, of industry-specific 'communities of practice'. Their capacity derives from three forms of knowing: knowing 'how' (technical expertise); knowing 'why' (motivation); and knowing 'whom' (networking). Universities promote the first of these, but less the second and third. The latter have been instrumental in New Zealand film. Although seeded by a particular individual - Peter Jackson - such communities of practice cannot be written off as one-offs. The conditions that spawned them, for example, economic rationalism, are not confined to New Zealand. In the developing world, and returning to countering brain drain, communities of practice can be seeded around, as the authors themselves put it, 'knowledge formats which have high Indigenous value but limited transferability to richer economies'. Thus, and echoing the contributions generally, we must persuade high achievers that there are opportunities to express their motivation at home. 


\section{Themes}

The contributions in this volume are diverse. In our recognition of, and respect for, that diversity, we often overlook similarities (Ofori-Dankwa and Tiermen, 2002). The most striking similarity across the papers as a whole is the idea of tolerating differences, and seeing them as sites for knowledge flow and capacity development. That idea is also implied by Neave (Neave, 2002), in his argument for 'disaggregation' in research, and research training systems, to allow for local variations in advance of potentially building back-up to general policy. Another way of picturing both global penetration and local assertiveness combined is as a global-local 'glocality' (Carr, 2004).

Contact between global and local systems, in a unique glocality, is a unifying element in all our readings. Included are academic diasporas and immigrant academics (Hugo), expatriate labor (McAuliffe and MacLachlan), the commercialization of intellectual property (McAuliffe and MacLachlan; Meyer and Evans), problem posing vs knowledge banking (Maluwa-Banda and MacJessieMbewe), fusion of foreign and traditional knowledge (Sinlarat, Marai et al), diversity paradigms (Nsamenang), 'blending global and local knowledge' (Bandawe), 'the interface' (Durie), and metaphors of 'boundaryless' careers with knowledge workers as bees that develop capacity in the hive (Inkson and Parker). Overall, the readings throughout this special issue point towards a general policy of encouraging both global and local knowledge systems together.

This entails understanding human motivation. Motivation means literally 'to move', and the glocal incentives to mobility captured in this volume range from salary and lifestyle to family support, cultural identity, and career. Those observations are broadly consistent with theories emerging in the managerial literature on global mobility (Carr et al., 2005). Encouraging an interface between global and local systems of knowledge has inherent potential to redress poverty (Sawamura, 2002). Neave (2002) describes how technologymediated partnerships between research teams spanning 'developed' and 'developing' economies have the potential to unlock global 'reserves of talent', for example, across the current digital divide in Africa. Such processes may contribute to reducing global inequities in poverty and wealth (Erasmus, 2002; Mneney, 2002), and indeed inequities in health (McAuliffe and MacLachlan, Bandawe, Durie). Others focus on education (Paitoon, Maluwa-Banda and MacJessie-Mbewe, Nsamenang). The remainder considers management of HR (Hugo, Meyer and Evans, Inkson and Parker) or a combination of all three (Marai et al). These foci are recognized as contributors to development in general, and poverty reduction in particular. In HE, they facilitate the university's role as critic and conscience of a global society. In the context of a United Nations' Millennium goal of reducing world poverty, facilitating that glocality - we believe - is the profoundest contribution of all. 


\title{
Acknowledgements
}

We thank the School of Psychology, at Massey University, New Zealand, for generously assisting this project. Thanks to Jude Fredricsen for her professional copyediting skills. We also thank the Provost's Fund at Trinity College, Dublin, for supporting this work.

\author{
Stuart C Carr ${ }^{\mathrm{a}}$ and Malcolm MacLachlan ${ }^{\mathrm{b}}$ \\ ${ }^{a}$ Massey University, Auckland, New Zealand \\ E-mail: s.c.carr@massey.ac.nz \\ ${ }^{b}$ Trinity College Dublin, Ireland \\ E-mail:mlachlan@tcd.ie
}

\section{References}

Carr, S.C. (2004) Globalization and Culture at Work: Exploring Their Combined Glocality, Dordrecht, Netherlands: Kluwer Academic Publishers.

Carr, S.C., Inkson, K. and Thorn, K.J. (2005) 'From brain drain to talent flow: a motivational theory of global careers', Journal of World Business (in press).

Enders, J. and Fulton, O. (eds.) (2004) Higher Education in a Globalizing World: International Trends and Mutual Observations, Dordrecht, Netherlands: Kluwer Academic Publishers.

Erasmus, A. (2002) 'Pitfalls, challenges, and triumphs: issues in an international capacity development project', Higher Education in Europe 27(3): 273-282.

Knight, J. (2003) 'Internationalization of higher education practices and priorities', 2003 IAU Survey Report. Paris: International Association of Universities (IAU).

MacLachlan, M. and Caball, M. (eds.) (2004) Social Science in the Knowledge Society, Dublin: The Liffey Press.

Marsella, A.J. (1998) 'Toward a global community psychology: meeting the needs of a changing world', American Psychologist 53: 1282-1291.

Mneney, E. (2002) 'Mechanisms for Implementation of Networking, Sharing Resources, and Dialogue', in I. Iya, N.S. Rembe and J. Baloro (eds.) Transforming South African Universities: Capacity Building for Historically Black Universities, Cape Town: Africa Institute of South Africa, pp. 122-129.

Neave, G. (2002) Research and Research Training Systems: Towards a Typology, UNESCO Forum Occasional Paper Series Paper No. 1. Paris: UNESCO.

Ofori-Dankwa, J. and Tiermen, A. (2002) "The effect of researchers' focus on interpretation of diversity data', Journal of Social Psychology 142(3): 277-293.

Olsen, M., Codd, J.A. and O'Neill, A.M. (2004) Education Policy: Globalization, Citizenship, and Democracy, London: Sage.

Potter, J. (2004) Global Knowledge Flows and Economic Development, Paris: OECD.

Sawamura, N. (2002) 'Local spirit, global knowledge: a Japanese approach to knowledge development in international cooperation', Compare 32(3): 339-348.

Schwartz, S.H. (1997) 'Values and Culture', in D. Munro, J.F. Schumaker and S.C. Carr (eds.) Motivation and Culture., New York: Routledge, pp. 69-84.

Tilak, J.B.G. (2002) 'Knowledge society, education, and aid', Compare 32(3): 297-310.

Varis, T., Utsumi, T. and Klemm, W. (eds.) (2003) Global Peace Through the Global University System, Hämeenlinna, Finland: University of Tampere Press. 